\title{
The Semiotics of Humiliation
}

\author{
Andi Rachmawati Syarif ${ }^{1}$, Nursidah ${ }^{2}$ \\ rachmasyarif@gmail.com \\ idha55@yahoo.co.id \\ 1Universitas Muhammadiyah Kendari, Indonesia \\ 2Universitas Hasanuddin, Indonesia
}

Received: 10 September 2020 Accepted: 29 November 2020

DOI: $10.24256 /$ ideas.v8i2.1569

\begin{abstract}
Being almost inseparable from human being, 'Humiliation' and 'dignity' must be considered as much more universal substance. Its counterpart must be regarded as having the same level of universality. However, is the fact that the form of both 'dignity' and 'humiliation' differ so much around the world, that the two terms probably represent the best argument for that there are big differences between cultures and nations. Since the experience of humiliation does not necessary result in an immediate feeling of being humiliated. Thus one of the core challenges is to find the solution of how 'humiliation' on the one hand represents something universal and on the other hand is the best argument for non-universality in the world. In this sense, the essay seems to be much easier to say something about the cause for humiliation instead of its effect on the victim. Yet, this essay attempts to point out how these terms might be understood in attempt at making them meaningful in itself and fruitful for empirical investigation.
\end{abstract}

Keywords: victim;dignity ;Humiliation; insult;, shamed

\section{Introduction}

'Humiliation' and 'dignity' must be considered as two basic aspects of humans. One can even say that without any dignity, there would be no 'human'. 'Humiliation', however, are partners for the lack of 'dignity' that is guaranteed(Pia et. al., 2020; Husum et. al. 2020). These two terms are so clear and so important to mankind that every culture throughout history seems to have an idea of what is meant by the two terms.

Indeed, there are quite few empirical studies that discuss aspect of humiliation. Previously studies, some, discuss the 'willingness to obey', and not much pinpointed 
the humiliation terms to be discussed (Adorno, Theodor W., Frenkel-Brunswik, Else, Levinson, Daniel J,; Sanford, R. Nevitt 1950-1997). These studies only discuss the term of 'damaging' and do not discuss much about 'humiliation'. Yet, it might be easier to discuss the cause of humiliation than its effect on individual.

Alludes to a little research on authoritarian-authoritarianism, which focuses on ideology as a methodological presupposition in inquiry. 'Personality' is not imagined as a universal entity that is not historic, but is instead defined as 'a way of thinking about people and society' (Adorno 1957/1997). 'Ideology' is the main definition of Adorno's philosophy and it refers to 'falseness' which gives character to individuals who try to understand the same society which they are part of. It might be said that a big difference in understanding something can cause a problem, and an understanding is not always more ideal than another. Differently, 'Shame' narratives analysis conducted shows that shame is a moral emotion which results from two main evaluative perceptions, involving moral sentiment and social reputation (Kasabova, 2017).

Understanding requires distance, but to get that distance to the community itself is almost impossible, because everyone is so closely intertwined in it. The existing at a certain time is the result of historical processes and contemporary social events. Like authority, humiliation must also be analyzed and understood in accordance with a particular time, society and culture.

The incident 9.11 in America on CNN as well as the survey conducted (Norwegian survey, 2001) showed that the attack carried out on the twin towers felt by the American population who experienced it as a direct reaction was not a 'humiliation'. But what came to mind at that moment was described by the words 'horrible', 'disgust', 'sinister', 'terrorism', 'sickness', 'evil',etc. it seems that the words that often appeared in media at the time were the expression of feelings of surprise. The population at that time more thought that the incident was an accident, they did not feel threatened to travel in the presence of the incident. They disagree with the statement which considers that the incident is a 'threat' to western democracy. This means that they consider themselves not as victims and assume that the incident was not a humiliation.

As their initial assumption was that the victims here were crashing plane, not buildings. Yet, after an official statement from the American government, changed their assumption, thus, that the incident was an attackand the twin tower building which is the icon of the American economy was victims, not the flight itself.

On one hand, young Norwegians feel sympathy for Americans because they feel that they have the same culture of thinking, but the survey shows that they do not consider the attack as a personal threat as felt by American society in general.

Hence the term 'insult' here should be understood as a particular discourse.Not when the terms insult used and made, it can be said that the incident could be categorized as an insult. And, that the community does not feel 'insulted' as a direct consequence of the attack, shows that the feeling of 'being insulted' arises when having and getting 'triggers or underlying things' (read; culture). 


\section{Discussion}

The experience of 'humiliation' is not always a direct result of feeling humiliated. It may be that the activation of symbols associated to humiliation is a necessary condition for having feelings of humiliate. Feeling 'humiliated', represents one side of a universal feeling, but on the other hand shows a lot of different forms.

Starting from a study conducted by Goffman which became the cornerstone of the study of social construction and self-manipulation to define 'behavior' (1956), especially when individual status is directly related to the status of other individuals.

Miller extends this dynamic by focusing on coding and deciphering 'self'(social processes, where the perpetrators show themselves the things they face, in situations where they act and plan their actions through their interpretation of these things ), particularly regarding the 'humiliation' (insult) - a complex emotional experience that conceptualization is often blurred through the replacement of synonym is wrong (embarrassment, shame, etc.) and the projections are not always empathetic intersubjectif (eg pity).

Because of its ubiquitous nature, 'humiliation' is partly defined by what we consider 'human', along with the desire we have to be included among these entities, as Goffman observed.

Society is governed by the principle that every individual who has certain social characteristics has the moral right to expect that others will respect and treat them in an appropriate manner (Goffman, 1956; Ibrahim and Sulaiman,2020). As a result, individuals automatically use moral demands on others, obliging them or other individuals to judge and treat them as their rights should be treated.

This then creates a situation based on a 'dramaturgical co-operation' (the play of life presented by humans, describing individuals and their daily interactions) where each individual asks others to treat themselves as part of their group or allow it treat themselves as part of their group. If the wish (unguarded request) is rejected, then the 'humiliation' (insult) will happened. In this paradigm, the desired social interaction and status acquisition involve oneself to the possibility of re-encoding personal 'values' which results in a decline in status or even loss. This vulnerability is found in the process of semiosis which leads to embarrassing experiences. In the case of image management semiotics, 'humiliation' can be seen as 'projected definition disturbance' or 'performance disruption' (performance disruption) (Goffman, 1956; Mikhael and Baskerville, 2019; Kalelioglu, 2019).

Examples that occur in 'miniature saga' (Clover, 1984); "Thorstein the Staff-Struct" is a popular masterpiece at Norton Anthology. In this story Thorstein experienced a discredit in the local community that gave him a 'symbol of stigma' when he was easily defeated by his rival, Thord, using a bat when riding a horse race. But Thorstein did not say anything about the incident and asked people who 
witnessed the incident not to tell his father.

This response implies that he considers the blow unintentional (and therefore there is no risk of humiliation for returning it), but it also shows his authority is limited because he has faced events that have the potential to embarrass him - and he is not the only person who can judge.

In fact, two witnesses teased him about the incident and gave him a 'nickname' which eventually led his father to declare that his decoding was wrong, that it was motivated by fear of public humiliation, and that Thorstein lost his status.

When Thorstein questions Thord about what the intentions behind his actions are, Thord insults Thorstein and insists that the incident was an act of contempt. Thorstein then killed Thord along with two witnesses who had insulted him about the beatings in retaliation for insults.

In the case above, the provision of a 'nickname' indicates a general gender-oriented phenomenon that could indicate a change in status from 'normal' to 'insult' (Goffman, 1963).

Because of this saga's phallocentric economy sexuality hierarchy, hinting that one treats others 'like women' through figurative forms of anal rape (symbolically staff-struck), will be a painful insult.

Miller (1993) then sees 'humiliation as a social practice' in the lens of social principles. In the case of gift-giving, Miller conceptualizes 'gift' in broad, abstract sense, so it can be said, for example, that Thorstein received an unwanted 'gift' from Thord.

By changing the contour of the 'gift', Miller significantly expands his relationship (gift) beyond the positive relationships that are normally associated with him.

After all, although everyone might have received an unwanted gift, this experience is usually not entirely polluting, or even prominent, in our general attitude regarding gift giving. In addition, Miller emphasized the extraordinary vulnerability that underlies gift-exchange, or the recipient of a gift is involved in a complicated situation where his status cannot be denied.

In this article, Miller considers that accepting gifts creates an undeniable obligation to return gifts with gifts. Miller identifies the semiotic component of this exchange which is often unmarked.

Clearly, accepting a gift means acknowledging the inclusion of the gift recipient in a particular social circle where gift giving contributes to the formation of individual values. As a result, he is obliged to pay for the gift, as Miller wrote, not because he received the gift but rather because it was identified with a group that has a unique social code of behavior.

Because receiving a gift, indicating membership in a 'group' (a group of individuals who work together in a routine), and the individual must participate, to maintain his status as part of a group or risk getting insulted.

Primarily, an individual can be placed in this situation at will through actions without the consent of others. Regarding the conditions above, Miller gives an 
example of the character from Egil's Saga.

In the story, after Egil returned from his journey and discovered that his friend and fellow poet, Einar, had given him a large gift, a very valuable shield. Egil responded by saying "Fuck him! Does he think I'll stand guard all night and compose poems about his shield? Bring my horse. I will catch up and kill him ".

As Miller points out, Egil illustrates that "gifts can be understood as insults."

Even though Einar has broken the existing rules on visiting opportunities by leaving a gift without personally giving it directly to Egil, he still succeeded in implying Egil in an unwanted and unintentional reciprocity where he had no choice but to participate to maintain his status.

In other words Einar has done a coding on Egil's social position (Egil is an honorable person who deserves a prize) which consequently puts Egil in a position owed to Einar. If this debt is not reciprocated (again, Miller states that repayment is an important part of the prize itself), then Egil will allow himself to be humiliated by others and against his will.

Miller (1993) added, that giving gifts well (so as not to offend) requires social competence. By knowing how to negotiate puzzles of meaning that might exist, a smart giver can eliminate the bad potential from the nature of gift giving, because gifts clearly have unfriendly potential.

Thus, participating in gift exchanges involves the same practical knowledge of semiotics as demanded by other local cultural practices, even though it is clear that the genre of the gift has its own specific contours.

An important idea in gift exchanges is the way in which reciprocity is carried out and implemented(Eriksson et. Al., 2020).

A particular component in the very complex gift-exchange that Miller raised in this article, "a gift leaves a definite return that is unexpected".

Because of "good manners" and the desire to establish and maintain social status dictate returns only through guessing (unilateral thinking) rather than asking how the response is appropriate, the returner always risks losing status, what Miller referred to in his article 'the game of honor' (the game of honor) contained in the gift exchange.

Although culture provides us with a variety of rules that govern small things in social interaction, they are not always well understood by all or even mutually agreed upon.

A simple example of the 'honor game' that often occurs to this day, one of them is 'invitation letter'. Offense often occurs due to trivial issues, which feel embarrassed by the way the invitation is delivered, whether it's a wedding invitation or another invitation.

The recipient of the invitation may feel humiliated if the person delivering the invitation, may said as 'an ordinary person', while the recipient of the invitation is 'leading person', has a social status in society, moreover has a kinship with the owner of intent. Then perhaps the recipient of the invitation will feel 
"underestimated" because it is not the intent of the owner who "directly" delivers the invitation.

Another real example, which has happened in an academic environment, is a fight that occurred between fellow students (happened at famous Uni in Indonesia). The cause of the fight was a senior who felt 'offended' by his junior, "slapped" by fellow students from different faculties. Because 'not accept' about the incident, then as 'seniors', they feel 'embarrassed' if they don't defend their juniors because the same thing means 'slap their head and embarrass' them.

Even more embarrassing, a fight broke out between senior lecturers and junior lecturers. The reason was because the proposal for 'senior lecturer was rejected' by 'junior lecturer' who was the chairman of the journal publishing agency, because 'did not accept' the proposal was rejected which made him feel 'ashamed' and 'lost face' among his colleagues, so angrily approached the junior lecturer later abused him blindly.

Miller (1993) pinpoint, "We all know the rules at a certain level of consciousness. However, knowing those rules consciously doesn't seem to correlate with how good we are in the world of gifts and invitations. "

As is possible for deviations from the markers to be always present, prizes always contain the potential to create a social disgrace if the decoder mismanages the compensation of a prize, which Mehlman (1972) says is a "floating signifier" that never has clear clarity.

We need to see ourselves properly socialized, and this illustration of acceptance is found in the signs and practices of positive sociability shown in gift exchanges (Miller, 1993).

Starting with experts' thoughts about some of the characteristics and uniqueness that define human speech, verbally, as the main point of human capacity to perceive, express and define "self", Jacobson (1974) categorizes the phenomenon of human semiosis: - the uniqueness of human speech lies in (1) creativity; (2) the ability to form abstractions, fiction, or general discussion in a community, which is not present on the speaker's side; (3) the hierarchical structure of essential constitutive elements as well as the dichotomy units that are unique and significant, and the division of the grammatical system into words and sentences or the coding of units and matrices; (4) use of propositions (affirmation and negation sentences); and (5) a hierarchy that can turn from diverse functions.

Mentalists see language further, that language or speech is seen as connecting conscious mental representations of external expressions to unconscious mental representations that function as messages. Frege (1892) assumed that language was in no way a psychological phenomenon. Rather language should be intended as a relationship between expressions, the world (possible worlds), and truth values. The foundation statement of meaning, departing from Tarski (1956), and 'mind' does not play a role in these conditions; language is considered as an objective abstract part of the world, similar to numbers.

What remains a question is how humans acquire and reach language. 
Furthermore, that language allows its speakers to reference the world, the conceptual world is relevant, not objective 'truly the world' (Jackendoff 1983; Lakoff 1987).

On the other hand, speakers can make references to all imaginary entities, such as angels, angels, saints, etc., as long as there is a concept attached to them. Full language with references forms entities that are formed only based on human conceptualizations, such as marriage, education level, political barriers, etc. So that it will not be able to reference something that was not conceptualized before.

The problem is how to equate the concept of each individual language user, because humans use language may be abstract and objective. This can be resolved, because speakers try to negotiate conditions, and give each other the opportunity to develop understanding between them. Because every language user has an innate capacity for the language and the concept of acquisition. Humans use language to communicate and state the world as they conceptualized.

\section{Conclusion}

Speaking of language use, the pragmatic perspective sees everything as meaning. Pragmatics focuses on the process of generating meaning (meaning generation). The basic aim is to find insight into meaningful language functions in human life. From this point of view, meaning is an intangible thing and its existence is difficult to determine. The first reason, in order to interpret a verbal communication, one must consider is how the attitude or action is appropriate to the context of the communication. Then, because the meaning is intangible, it tends to be impossible to convey the meaning explicitly. While many types of meaning are indirect or unliterally said (presupposition, implicature, indirect speech act). These are the things that often give birth to differences in messages, concepts, and interpretations of communication in the community that have the potential to trigger conflict in social interaction.

However, some phenomena that occur, tend to reverse the theories that exist in connection with the three aspects above; message, concept and interpretation. It is said, social conflicts occur because of the tendency of difficulties in conveying meaning explicitly or explicitly. The meaning should not give birth to a different interpretation. We still remember the Sonya Depari case (claiming to be a General's daughter). In this case, what happens is Name Dropping (English term), which translates literally to "drop name". In the Indonesian language it can be interpreted as "taking name", it is normal for family names, acquaintances, famous people or even officials. This is not only exclusive to Indonesians, but in other countries also doing the same thing. The question is why the symptoms of name dropping arise earlier.

It is possible because of the pressure associated with social status, whether to raise social status (riveting) or because they feel a threat to the status they already have (humiliation). In the case of Sonya Depari, a feeling of being threatened by his 
status encourages name dropping, with the intention of securing his status. Until the words (utterances) are used as the jargon "I mark you".

Sonya Depari, became one of the "markers" of the many "markers" of cases of reality in society. The case of "the nephew" who wants to be the king of Gowa, the Dul case (son of Ahmad Dani), the Rasyid case (son of the Vice President) and other names are just "markers" of the relationship between elements of reality that will always be remembered, judged and bullied by the public without touching the real problem. The real problem is when property, throne / position, abuse of power whose level is still above the law. These elements can be called "signs".

The fundamental paradox, however, is the fact that the form of both 'dignity' and 'humiliation' differ so much around the world, that the two terms probably represent the best argument for that there are big differences between cultures and nations.

In the further perspective essay, problems are not only connected to the term 'humiliation' but also to the term 'culture' as well. Thus, how culture might be understood in an attempt at making the term meaningful in itself and fruitful for empirical investigations. In addition, theories of signs may be fruitful in further investigations of humiliation

\section{References}

Adorno, Theodor W., Frenkel-Brunswik, Else, Levinson, Daniel J.; Sandford, R. Nevit (1997). The Authoritarian Personality, University of California, Berkeley

Adorno, Theodor W. (1997). Gesammelte Schriften Band 9.1, Sociologischen Schriften II, ErsteHôllfte, Wissenschaftliche Buchgesellschaft, Darmstadt.

Crawford, B. \& Lipschutz, R.D. (Eds). (200). The Myth of 'Ethnic Conflict': Politics, Economics and 'Cultural' Violence, University of California, Berkeley.

Eriksson, M., Eriksson, U., \& Linder, C. (2020). Using social semiotics and variation theory to analyze learning challenges in physics: a methodological case study. European Journal of Physics, 41(6), 065705.

Halliday, M.A.K. (1978). Language as Social Semiotic: The Social Interpretationof Language and Meaning. Maryland. University Park Press.

Husum, T. L., Thorvarsdottir, V., Aasland, O., \& Pedersen, R. (2020). 'It comes with the territory'-Staff experience with violation and humiliation in mental health care-A mixed method study. International journal of law and psychiatry, 71, 101610.

Hodge, R and G. Kress. (1988). Social Semiotics. Cambridge: Polity

Hofstede, G. (1980). Culture's consequences: International differences in work-related values, CA: Sage, Newberry Park.

Ibrahim, I., \& Sulaiman, S. (2020). Semiotic Communication: An Approach of Understanding A Meaning In Communication. International Journal of Media and Communication Research, 1(1), 22-31.

Kalelioğlu, M. (2019). From Semantics to Semiotics. Chinese Semiotic Studies, 15(3), 317-348. 
ISSN 2338-4778 (Print) ISSN 2548-4192 (Online)

Kasabova, A. (2017). From Shame to Shaming: towards an Analysis of Shame Narratives; Open Cultural Studies 2017; 1: 99-112. DE GRUYTER.

Mikhaeil, C. A., \& Baskerville, R. L. (2019). Using semiotics to analyze representational complexity in social media. Information and Organization, 29(4), 100271.

Pia, T., Galynker, I., Schuck, A., Sinclair, C., Ying, G., \& Calati, R. (2020). Perfectionism and Prospective Near-Term Suicidal Thoughts and Behaviors: The Mediation of Fear of Humiliation and Suicide Crisis Syndrome. International journal of environmental research and public health, 17(4), 1424.

Rampton, Ben (2001) Language Crossing, Cross-talk, and Cross-disciplinarity in Sociolingusitics, Kings College : London.

Simpkins, Scott. (1994). The Semiotic of Humiliation. The American Journal of Semiotics; Kent. Semiotic Society of America. Kent. United States. ISSN: 02777126. ID. 213748552 Vol. 11, Iss. 3/4, (1994): 307-314 